\title{
Six simple guidelines for introducing new genera of fungi
}

Else C. Vellinga ${ }^{1}$, Thomas W. Kuyper ${ }^{2}$, Joe Ammirati ${ }^{3}$, Dennis E. Desjardin ${ }^{4}$, Roy E. Halling ${ }^{5}$, Alfredo Justo ${ }^{6}$, Thomas Læssøe ${ }^{7}$, Teresa Lebel ${ }^{8}$, D. Jean Lodge ${ }^{9}$, P. Brandon Matheny ${ }^{10}$, Andrew S. Methven ${ }^{11}$, Pierre-Arthur Moreau ${ }^{12}$, Gregory M. Mueller ${ }^{13}$, Machiel E. Noordeloos ${ }^{14}$, Jorinde Nuytinck ${ }^{14}$, Clark L. Ovrebo ${ }^{15}$, and Annemieke Verbeken ${ }^{16}$

${ }^{1}$ Department of Plant and Microbial Biology, University of California at Berkeley, Berkeley, CA 94720-3102, USA; corresponding author e-mail: ecvellinga@comcast. net

${ }^{2}$ Department of Soil Quality, Wageningen University, P.O. Box 47,6700 AA Wageningen, The Netherlands; corresponding author e-mail: thom.kuyper@wur.nl

${ }^{3}$ Department of Biology, University of Washington, Seattle, WA 98195-1800, USA

${ }^{4}$ Department of Biology, San Francisco State University, 1600 Holloway Avenue, San Francisco, CA 94132, USA

${ }^{5}$ Institute of Systematic Botany, New York Botanical Garden, 2900 Southern Boulevard, Bronx, NY 10458, USA

${ }^{6}$ Department of Botany, Institute of Biology, National Autonomous University of Mexico, 04510 Mexico City, Mexico

${ }^{7}$ Department of Biology/Natural History Museum of Denmark, University of Copenhagen, Universitetsparken 15, 2100 Copenhagen Ø, Denmark

${ }^{8}$ Royal Botanic Gardens Victoria, Birdwood Ave, Melbourne 3004, Australia

${ }^{9}$ Center for Forest Mycology Research, Northern Research Station, USDA-Forest Service, Luquillo, PR 00773-1377, USA

${ }^{10}$ Department of Ecology and Evolutionary Biology, University of Tennessee, Knoxville, TN 37996-1610, USA

${ }^{11}$ Department of Biological Sciences, Eastern Illinois University, Charleston, IL 61920, USA

${ }^{12}$ Département des Sciences Végétales et Fongiques, Faculté des sciences pharmaceutiques et biologiques, Université de Lille, 59006 Lille, France

${ }^{13}$ Chicago Botanic Garden, 1000 Lake Cook Road, Glencoe, IL 60022, USA

${ }^{14}$ Naturalis Biodiversity Centre, P.O. Box 9517, 2300 RA Leiden, The Netherlands

${ }^{15}$ Department of Biology, University of Central Oklahoma, Edmond, OK 73034, USA

${ }^{16}$ Ghent University, Department of Biology, K.L. Ledeganckstraat 35, 9000 Gent, Belgium

Abstract: We formulate five guidelines for introducing new genera, plus one recommendation how to publish the results of scientific research. We recommend that reviewers and editors adhere to these guidelines. We propose that the underlying research is solid, and that the results and the final solutions are properly discussed. The six criteria are: (1) all genera that are recognized should be monophyletic; (2) the coverage of the phylogenetic tree should be wide in number of species, geographic coverage, and type species of the genera under study; (3) the branching of the phylogenetic trees has to have sufficient statistical support; (4) different options for the translation of the phylogenetic tree into a formal classification should be discussed and the final decision justified; (5) the phylogenetic evidence should be based on more than one gene; and (6) all supporting evidence and background information should be included in the publication in which the new taxa are proposed, and this publication should be peer-reviewed.

Key words: basidiomycetes, molecular systematics, nomenclature, phylogenetics, taxonomy,

\section{INTRODUCTION}

In 2014 and the first six months of 2015 alone, more than 20 new genera in Boletaceae were proposed. Most of these new generic names encompass species that occur in North America and Europe and that have been called "Boletus" for a long time.

The numbers for Agaricales are comparable: we counted around 25 new generic names published in that same time period, most of them white-spored, with six new genera for species we used to call Clitocybe, five new genera in Lyophyllaceae, and three new ones in Psathyrellaceae. The largest genus by far, Cortinarius, was not affected. In contrast, probably some 6-7 genera have now been subsumed under Cortinarius. With many new generic names being introduced for well-known species, it comes as an even larger surprise to note that there were very few new genera described based on newly discovered species with unique morphological character combinations. Examples of the latter are Cercopemyces crocodilinus from the Rocky Mountains (USA) and Hymenoporus paradoxus from China (Baroni et al. 2014, Tkalčec et al. 2015).

The underlying principle for recognition of a genus, or any taxonomic rank for that matter, is monophyly (Hennig 1950, 1965). In the past this was extremely difficult to demonstrate in fungi, as the number of morphological characters that could be used was limited. It was also unknown whether some of the characters that were used, such as the formation of sequestrate or gastroid basidiomes, had a low evolvability, justifying recognition as separate genera, or a high evolvability, which then downplays its relevance in a phylogenetic context.

The flood of these recent new generic names has mainly been prompted by molecular-phylogenetic research and the resulting phylogenetic trees. It has led to re-evaluation of characters; in many cases sequestrate and gastroid forms were shown to have higher evolvability than assumed, justifying the subsumption of such genera under existing genera; for example in Suillus (Kretzer \& Bruns 1997), Cortinarius (Peintner et al. 2002), Lactarius (Eberhardt \& Verbeken 2004, Kirk 2015), Russula (Lebel \& Tonkin 2007), Lepiota (Ge \& Smith 2013), and Boletus (Nuhn et al. 2013). Lichenization had low evolvability in basidiomycetes, justifying recognition of Lichenomphalia as a separate genus for species that were previously placed in three genera (Redhead et al. 2002).

However, such phylogenetic analyses have to a smaller extent than was hoped solved the problems of genus delimitation and recognition. Analyses have shown that several well-known genera remain paraphyletic, such 
as Boletus (Nuhn et al. 2013, Wu et al., 2014) and Psathyrella (e.g, Padamsee et al. 2008). Dealing with the issue of paraphyly then set the mycological community on two, rather divergent, paths. These divergent approaches mirrored old distinctions of splitters and lumpers. One pathway was to take small monophyletic groups as the basis for new genera, without too much concern about the remainder of the original genus. This is a practice clearly shown by the treatment of Boletus and Clitocybe. Separation of one small monophyletic group often set into motion a splitting snowball, as in Xerocomellus (Gelardi et al. 2015, Vizzini 2015). Unfortunately, recognition of such small genera sometimes contributed to the formation of paraphyletic genera, as in the case of Resupinatus which became paraphyletic because of the recognition of $R$. vetlinianus in a separate genus Lignomyces (Petersen et al. 2015). The second approach was taken in Entoloma and Clitopilus (Co-David et al. 2009), where deliberately a broad genus concept was chosen (though other authors opted for smaller genera (e.g. Largent 1994, Kluting et al. 2014). Other examples are Amanita (Justo et al. 2010) and Cortinarius (Peintner et al. 2001) where sequestrate and gastroid species were included in genera with predominantly agaricoid basidiomes. It is an interesting question how this divergence should be explained; certainly, the existing taxonomy of the group in question plays a big role. In the boletes, for instance, many previously published generic names for well supported genera, such as Leccinum and Strobilomyces, were already available, and the proposal of new genera was (consequently) considered acceptable.

\section{PRINCIPLE CONCERNS}

We find several of the recent trends in mycological taxonomic research on basidiomycete fungi disturbing:

(1) In several groups, the translation from a phylogenetic tree into a classification is taken into extremes, where every single clade is recognized as a separate genus. This does not increase insight in the evolutionary history of the group in question, only inflates the taxonomic framework. From a formal phylogenetic perspective it may not matter whether we have one family (e.g. Boletaceae), with more than a hundred genera, or whether we have one genus (e.g. Boletus s. lat.) with many infrageneric units, formally named or not. In the case of the boletes, inclusion of more sequences from more taxa may impact the phylogeny, as the resolution of the phylogeny of Boletaceae is low at many branches (Nuhn et al. 2013, Wu et al. 2014). We strongly advocate that different options are explored and discussed, instead of using a boilerplate model in which every monophyletic clade is translated into a genus.

(2) Several of the new genera are erected solely based on phylogenetic evidence provided by one or two gene regions, sometimes only nrITS sequences that do not lend themselves to higher level phylogenies (Bruns 2001).

(3) More and more rapid on-line, nonpeer-reviewed publications appear without any supporting evidence for the newly described taxa.

We therefore have formulated and present here criteria by which the phylogenetic studies and the publications that present the data from those studies should be tested before being accepted.

\section{PROPOSED GUIDELINES}

Some of our proposed guidelines are so self-explanatory and obvious to us that it seems superfluous to present them here; nevertheless, examples that are in conflict with these recommendations are surprisingly easy to find. The examples we present show how easy it is to meet these standards. We realize that practical issues, such as lost original type specimens, or material that does not easily yield DNA sequences may interfere with perfection, but one should at least try, and discuss failures. We emphasize the importance of exploring different classification options and giving arguments for the proposed new taxonomies. The examples we present are taken from the literature on basidiomycete fungi, but could equally have been chosen from the ascomycete literature.

The first five criteria relate to the underlying science; the first two criteria are equally important, and we put less emphasis on the next three. Nevertheless, it goes without saying that contradiction of any of these criteria should be avoided. We recommend first of all that researchers use these guidelines, but also that reviewers and editors of taxonomic journals use these criteria in their assessments of submitted manuscripts.

The sixth criterion concerns the way the results are published and presented to the scientific world.

\section{All genera that are recognized} should be monophyletic, not only the one that is the focus of the study, but also the group from which it is separated and the group to which it is added (the reciprocal monophyly criterion).

Examples:

(i) When Macrolepiota was split into a monophyletic core Macrolepiota with $M$. procera as its type species, and a second group containing $M$. rachodes, the latter was moved to Chlorophyllum that in itself was only monophyletic by also including Endoptychum agaricoides (Vellinga et al. 2003) and all necessary nomenclatorial changes were made (Vellinga 2002. Vellinga \& de Kok 2002).

(ii) The genus Porpoloma was found to be highly polyphyletic and split into four genera (Sánchez-Garcia et al. 2014). It was essential for the application of names to clades to sequence the type species of Porpoloma (see Recommendation 2).

Unfortunately, many studies do not reach this standard, as it is very easy to expel species from a genus, without taking into account the monophyly of the target group. Especially in cases of poor resolution in a phylogeny, erection of very small monophyletic genera will create more and ever more messy paraphyletic units, from which the next separation of a new genus can already be predicted.

\section{The coverage of the phylogenetic tree has to be broad.}

Coverage needs to be broad in terms of the: (a) number of species - it is important to remember that a phylogenetic tree only gives information on those taxa that are included in it, and that all statements on relationships are relative, and not absolute, unless all known taxa are included; (b) geographic distribution of the taxa - a phylogeny based on species from temperate areas of North America and Europe, is not informative 
if the group in question is represented by many more species in tropical Africa, Asia, and Australia; and (c) the data base should include type species of all genera that are being included, as the placement of the type species decides which name to use for a genus.

Examples:

(i) The genus Anamika was shown to fall in the middle of Hebeloma when specimens from Australia were added to the phylogeny mainly based on Eurasian species (Rees et al. 2013).

(ii) Only by including the type species of Pachylepyrium in the phylogenetic analyses, could the position of $P$. carbonicola and $P$. funariophilum unambiguously be determined (Matheny et al. 2015).

(iii) The position of Marasmius sect. Hygrometrici was determined by analyses that explicitly included the types of the genus Marasmius (and hence of sect. Marasmius) and sect. Hygrometrici (Jenkinson et al. 2014).

(iv) The type of Rubinoboletus always clusters with Chalciporus, hence the genus is subsumed into Chalciporus (Nuhn et al. 2013).

3. The branching of the phylogenetic trees should have sufficient and strong statistical support.

Weak support (or even absence of statistical support) of proposed new genera indicates that alternative classifications cannot be rejected. And so the advice is: 'in dubiis abstine”, when in doubt refrain from proposing new genera.

\section{Example:}

Lenzites warneri occupies an isolated and unsupported position within Trametes s. lat.; Welti et al. (2012) refrained from introducing a new generic name for this species, as it also does not have discriminating morphological characters. Justo \& Hibbett (2011) also did not recognize it as a separate genus either, but included it within their concept of Trametes, which is broader than that of Welti et al. (2012).

\section{A list of options should be} discussed, different options should be tested, and arguments for the final decision given.

Phylogenetic methods often allow, even in well-resolved trees, more than one formal classification with monophyletic groups. Therefore different options should be presented and discussed.

Examples:

(i) Justo \& Hibbett (2014), and Justo (2014) discussed the different options for and consequences of recognizing ten or five genera or just one genus within Trametes s. lat., ultimately opting for a one-genus solution.

(ii) Halling et al. (2015) tested different options for the circumscription of Boletellus and delimitation of that genus in regard to Heimioporus; these authors included the species that form a grade at the base of the core Boletellus within that genus, instead of describing new genera for each clade.

(iii) Buyck et al. (2008) presented and tested 15 different options for the phylogeny of the different clades in Lactarius and Russula, before settling on the solution of breaking up Lactarius into two genera, Lactarius and Lactifluus, and recognizing Russula sect. Ochricompactae as a separate genus, Multifurca.

(iv) Lodge et al. (2014) discussed options for recognition of one or three genera for Gliophorus, Porpolomopsis, and Neohygrocybe.

5. The phylogenetic evidence has to be based on more than one gene, preferably protein coding genes in addition to gene regions of the SSUITS-LSU repeat.

The different gene regions that are commonly used in basidiomycete classifications all have different evolutionary histories, and hence they have different resolving power at different levels. Phylogenies based only on nrITS sequences have not only to be approached with a large dose of skepticism, but in fact should no longer be accepted as the basis for new genera. This marker is the universal barcode for fungal species recognition (Schoch et al. 2012), and it performs this role generally well because of sufficiently large variation between related species within many, but not all, fungal groups; the price we pay for that species-level accuracy is that nrITS is unalignable over more distantly related taxa (Bruns 2001). In the past, it was debated what was better, to have more taxa/collections analysed or more genes for fewer taxa (Greybeal 1998); with lower sequencing costs and faster computers, the answer is: more taxa and more genes. However, phylogenies based on whole genomes are still rare and include only a small number of species (e.g. Dentinger et al.2015); and of course, whole genome comparisons will be faced with the same issues as the phylogenies based on a hand-full of genes.

Example:

In an analysis of three loci (nLSU, nSSU, and $\mathrm{rpb} 2$ genes) from a wide range of taxa in the tricholomatoid clade, Sánchez-Garcia et al. (2014) recognized the new genera Corneriella, Albomagister, Pogonoloma, and Pseudotricholoma all with full statistical support.

\section{All supporting evidence and} background information should be included in the publication in which the new taxa are proposed; and secondly, this publication should be peer-reviewed.

The first part of this guideline is prompted by the appearance of very short publications associated with one of the official taxon registration sites, without any supporting evidence nor illustrations, sometimes with a link to another, often personal, web site where the supporting information (e.g. a phylogenetic tree) can be found. Communication of the results of science is not a one-time event. A basic principle of science is that the results are verifiable by others. If in future researchers cannot go back to the whole set of data and information, that principle cannot be applied. This situation is the same as in experimental studies where the cultures used are not preserved thereby rendering the experiments unrepeatable, and in field reports where no vouchers are retained. Paper publications of the past provided and continue to provide a source of information that can always be consulted; putting that information on line in official library depositories such as JSTOR is an extra safe guard.

Peer review, though not waterproof, and always debated (see e.g., http://www. nature.com/nature/peerreview/debate/) is recommended as quality control before publication. The function of peer review in the case of taxonomic novelties is not to exercise censorship of taxonomic decisions, but to judge new genera against these principles to which the mycological community should adhere. 


\section{CONCLUSIONS}

We encourage all mycologists undertaking phylogenetic studies around the generic level to adhere to these guidelines, and further invite editors and peer reviewers to bear them in mind when considering a work for publication.

In recognizing that these problems are wide-ranging in mycology and may frustrate communication within the subject, we commend a cautious approach to introducing changes at generic rank.

Finally, we welcome and foresee critical assessments of introductions of new taxa at all taxonomical levels, especially families and orders, in all groups of fungi.

\section{REFERENCES}

Baroni TJ, Kropp BR, Evenson VS, Wilhelm M (2014) Cercopemyces crocodilinus, a new genus and species related to Ripartitella, is described from North America. Mycologia 106: 785-796. Bruns TD (2001) ITS reality. Inoculum 52 (6): 2-3. Buyck B, Hofstetter V, Eberhardt U, Verbeken A, Kauff F (2008) Walking the thin line between Lactarius and Russula: the dilemma of Russula sect. Ochricompactae. Fungal Diversity 28: 15-40.

Co-David D, Langeveld D, Noordeloos ME (2009) Molecular phylogeny and spore evolution of Entolomataceae. Persoonia 23: 147-176.

Dentinger BTM, Gaya E, O’Brien H, Suz LM, Lachlan R, Díaz-Valderrama JR, Koch RA, Aime MC (2015) Tales from the crypt: genome mining from fungarium specimens improves resolution of the mushroom tree of life. Biological Journal of the Linnean Society: http:// dx.doi.org/10.1111/bij.12553

Eberhardt U, Verbeken A (2004) Sequestrate Lactarius species from tropical Africa: $L$. angiocarpus sp. nov. and $L$. dolichocaulis comb. nov. Mycological Research 108: 1042-1052.

Ge Z-W, Smith ME (2013) Phylogenetic analysis of rDNA sequences indicates that the sequestrate Amogaster viridiglebus is derived from within the agaricoid genus Lepiota (Agaricaceae). Mycological Progress 12: 151-155.

Gelardi M, Vizzini A, Ercole E, Horak E, Ming Z, Li T-H (2015) Circumscription and taxonomic arrangement of Nigroboletus roseonigrescens gen. et sp. nov., a new member of Boletaceae from tropical south-eastern China. PLOS One 10 (8): e0134295.

Greybeal A (1998) Is it better to add taxa or characters to a difficult phylogenetic problem? Systematic Biology 47: 9-17.

Halling RE, Fechner N, Nuhn M, Osmundson T, Soytong K, Arora D, Binder M, Hibbett
D (2015) Evolutionary relationships of Heimioporus and Boletellus (Boletales), with an emphasis on Australian taxa including new species and new combinations in Aureoboletus, Hemileccinum and Xerocomus. Australian Systematic Botany 28: 1-22.

Hennig W (1950) Grundzüge einer Theorie der phylogenetischen Systematik. Berlin: Deutscher Zentralverlag.

Hennig W (1965) Phylogenetic systematics. Annual Review of Entomology 10: 97-116.

Jenkinson TS, Perry BA, Schaefer RE, Desjardin DE (2014) Cryptomarasmius gen. nov. established in the Physalacriaceae to accommodate members of Marasmius section Hygrometrici. Mycologia 106: 86-94

Justo A, Morgenstern I, Hallen-Adams HE, Hibbett DS (2010) Convergent evolution of sequestrate forms in Amanita under Mediterranean climate conditions. Mycologia 102: 675-688.

Justo A, Hibbett DS (2011) Phylogenetic classification of Trametes (Basidiomycota, Polyporales) based on a five-marker dataset. Taxon 60: 1567-1583.

Justo A (2014) The taxonomy of Turkey Tails (Trametes) and related polypores: One genus or too many? Mycophile 54 (4): 8-10.

Kirk PM (2015) Nomenclatural novelties. Index Fungorum 278.

Kluting KL, Baroni TJ, Bergemann SE (2014) Towards a stable classification of genera within the Entolomataceae: a phylogenetic re-evaluation of the Rhodocybe-Clitopilus clade. Mycologia 106: 1127-1142.

Kretzer A, Bruns TD (1997) Molecular revisitation of the genus Gastrosuillus. Mycologia 89: 586-589.

Largent DL (1994) Entolomatoid fungi of the western United States and Alaska. Eureka, CA: Mad River Press .

Lebel T, Tonkin JE (2007). Australasian species of Macowanites are sequestrate species of Russula (Russulaceae, Basidiomycota). Australian Systematic Botany 20: 355-381.

Lodge DJ, Padamsee M, Matheny PB, Aime MC, Cantrell SA et al. (2014) Molecular phylogeny, morphology, pigment chemistry and ecology in Hygrophoraceae (Agaricales). Fungal Diversity 64: 1-99.

Matheny PB, Moreau P-A, Vizzini A, Harrower E, De Haan A, Contu M, Curti M (2015) Crassisporium and Romagnesiella: two new genera of dark-spored Agaricales. Systematics and Biodiversity 13: 28-41.

Nuhn ME, Binder M, Taylor AFS, Halling RE, Hibbett DS (2013) Phylogenetic overview of the Boletineae. Fungal Biology 117: 479-511.

Padamsee M, Matheny PB, Dentinger DTM, McLaughlin DJ (2008). The mushroom family Psathyrellaceae: evidence for large-scale polyphyly of the genus Psathyrella. Molecular Phylogenetics and Evolution 46: 415-429.

Peintner U, Moser MM, Vilgalys R (2002) [“2001”] Thaxterogaster is a taxonomic synonym of Cortinarius: new combinations and new names. Mycotaxon 81: 177-184.

Petersen RH, Psurtseva N, Zmitrovich I, Chachuła P, Arslanov S, Hughes KW (2015) Lignomyces, a new genus of pleurotoid Agaricomycetes. Mycologia 107: 1045-1054.

Redhead SA, Lutzoni F, Moncalv J-M, Vilgalys R (2002).Phylogeny of agarics: partial systematics solutions for core omphalinoid genera in the Agaricales (euagarics). Mycotaxon 83: 19-57.

Rees BJ, Midgley DJ, Marchant A, Perkins A, Orlovich DA (2013) Morphological and molecular data for Australian Hebeloma species do not support the generic status of Anamika. Mycologia 105: 1043-1058.

Sánchez-Garcia M, Matheny PB, Palfner G, Lodge DJ (2014) Deconstructing the Tricholomataceae (Agaricales) and introduction of the new genera Albomagister, Corneriella, Pogonoloma and Pseudotricholoma. Taxon 63: 993-1007.

Schoch CL, Seifert KA, Huhndorf S, Robert V, Spouge JL, Levesque CA, Chen W, Fungal Barcoding Consortium (2012) Nuclear ribosomal internal transcribed spacer (ITS) region as a universal DNA barcode marker for Fungi. Proceedings of the National Academy of Sciences, USA 109: 6241-6246.

Tkalčec Z, Mešić A, Den C-Y, Pleše B, Ćetković H (2015) Hymenoporus paradoxus gen. et sp. nov., a striking fungus of the family Omphalotaceae (Agaricales, Basidiomycota) with tubular hymenophore. Phytotaxa 204: 203-212.

Vellinga EC (2002) New combinations in Chlorophyllum. Mycotaxon 88: 415-417.

Vellinga EC, de Kok RPJ (2002) (1539) Proposal to conserve the name Chlorophyllum Massee against Endoptychum Czern. (Agaricaceae). Taxon 51: 563-564.

Vellinga EC, de Kok RPJ, Bruns TD (2003) Phylogeny and taxonomy of Macrolepiota (Agaricaceae). Mycologia 95: 442-456.

Vizzini A (2015) Nomenclatural novelties. Index Fungorum 244.

Welti S, Moreau OA, Favel A, Courtecuisse R, Haon M, Navarro D, Taussac S, Lesage-Meessen L (2012) Molecular phylogeny of Trametes and related genera, and description of a new genus Leiotrametes. Fungal Diversity 55: 47-64.

Wu G, Feng B, Xu J, Zhu X-T, Li Y-C, Zeng N-K, Hosen MI \& Yang ZL (2014) Molecular phylogenetic analyses redefine seven major clades and reveal 22 new generic clades in the fungal family Boletaceae. Fungal Diversity 69: 93-115. 